\title{
Research on the Development of Chinese market Based on 4Ps Marketing Mix
}

\author{
Hong Ke, Lingyang Li
}

School of Management, Tianjin University of Technology, Tianjin, 300384, China

lilingyang1030@163.com

\begin{abstract}
Keywords: the Development of Chinese market, 4PS Marketing Mix, Cultural Marketing
\end{abstract}
\begin{abstract}
In 2001, after joining the World Trade Organization, China makes further integration into the multilateral trading system in the world by opening up a broader market. Since then, more and more multinational companies make direct investment in China in order to develop Chinese market. In the face of the different cultural backgrounds between host and home country, establishing a correct and accurate cross-cultural marketing strategy can help the multinationals to develop and dominate the market in China successfully. In this thesis, I analyzed Chinese cultural environment and combined the 4Ps marketing mix with case analysis together to illustrate the characteristics of cross-cultural marketing strategy of multinational companies in China and get some inspiration at last.
\end{abstract}

\section{Introduction}

Under the background of economic globalization, many multinational companies think investment in China as an important node to implement the Global Strategy. They constantly make new development strategy to respond to the rapidly changing Chinese market, so that they can keep an invincible position in the fierce competition. Cultural environment is extremely important and a factor can be easily neglected, and cultural differences often become invisible barriers of transnational business. Therefore, analyzing the Chinese culture's characteristics and its impact on marketing activities in China, treating cross-cultural conflict correctly, and reducing the uncertainties in the cultural environment can improve its ability to adapt to the culture in the Chinese market and contribute to the success of the marketing activities of multinational companies in China [1].

\section{Chinese Cultural Characteristics}

In the marketing activity of multinational companies developed in China, they should notice Chinese cultural characteristics to avoid its marketing activities in breach of traditional Chinese culture, customs, religious beliefs, values, laws and regulations, and the eventual purpose of cross-cultural marketing is to "think globally and act locally."

As a multi-ethnic country with a large population, China attaches great importance to collectivism. This is mainly reflected in the Chinese people's concern for the family and the collective where they stay in. In addition, Chinese believed the kindheartedness and fealty of Confucian since ancient times. This leads to the result that the Chinese often do things honestly, follow rules, are not in favor of a hero, and do not come to the fore. Chinese culture emphasizes thrift, and being tough. Chinese people often stress perseverance, hard-working in order to achieve the goal. These represent a long-term oriented culture and ideology. Therefore, the Chinese people give more admiration to those people and things which grow from adversity, perseverance, and gradually become successful .These are the multinational companies in China should be noted when they do cross-cultural marketing to avoid cultural conflict [2].

When multinational companies market in China, what they faced is an extremely unfamiliar cultural environment which is very different from western culture. It will surely increase the difficulty of marketing. Multinational companies in China must treat the similarities and differences 
between Chinese culture and the original culture that the corporate familiar with carefully, in order to carry out marketing activities successfully.

\section{Cross-cultural Marketing Strategy of Multinational Companies in China}

In the process of transnational business in a different cultural background and geographical environment, multinational companies faced unprecedented opportunities and challenges inevitably. Positive cross-cultural marketing strategy is to ensure the successful operation of multinational corporations in the cross-cultural and cross-boundary case. It has particular relevance to the Chinese market which is being integrated into the global economy [3].

Product Strategy. The direct extension strategy refers to selling existing products in the home country to the market of China without change. Since these products in the home country have already been standardized, this strategy is also called standardization strategy. If direct extension strategy can be used in international marketing, it will benefit the enterprises a lot. First, enterprises do not need to pay additional product research and development expenses and add new manufacturing equipment during production, thereby reducing business investment; Second, the products can be mass-produced and the costs can be reduced to achieve the economies of scale; Third, it can adapt to customer travel and relocation requirements, so that the same product can be found everywhere.

The product reorientation strategy refers to change the products sold in the home country according to the Chinese cultural characteristics and then put it into the Chinese market. This advantage of this strategy is that the corporation can adapt to the market demand in different cultural backgrounds by increasing a little in investment [4]. And therefore the majority of multinational companies in China prefer to use this strategy. The core of the strategy is to change the original product for local market requirements. Product changes in the following areas: functionality changes; quality change; appearance change; trademark change; packaging change; label change; changes in the use conditions; combination of changes.

Channel Strategy. Chinese market has particularity and complexity. Its commercial system is fragmented, the market is not standardized, and there is a gap between the urban and rural channel structure. In this context, market positioning, distribution channels, communication, service strategy have their uniqueness. Now, multinational companies recognize that only control the sales channels can they be able to win in the competition [5]. In order to improve the degree of localization of the sales channels, some multinationals cooperate with local enterprises in China to take use of its profound understanding to the Chinese market; Some vigorously promote the localization of services strategy to provide local services, establish a nationwide sales and service network; and some companies change the original channel according to characteristics of the Chinese market.

Due to limited funding and other reasons, multinationals will first consider using the country's ready-made distribution system to sell products. Thus can use middlemen's business relationships, experience and professional advantages, eliminate the barrier of language and social customs. For their own sales organizations, they neither need to invest a lot of manpower, material nor financial resources. It help them to reduce the risk and win the market. In addition to entrust local middlemen, more multinational companies use another channel strategy to establish a distribution network. Many multinational companies do not want to split part of the profit to intermediate suppliers in order to compete for the international market more effectively. And in order to make the business and profit stable, many large companies often establish their own overseas sales organization to expand sales and to strengthen the control of the distribution channels. Multinational companies committed to establish their own distribution channels to maintain because they think the level of service, marketing capability of foreign distributors is not assured. Some multinational companies in China prefer to establish their own distribution networks in foreign markets. 


\section{Revelation from Cross-cultural Marketing Strategy of Multinationals Applied in China}

Revelation to Product Strategy. The product is the core part in the marketing mix. In the multinational marketing strategy, brand names, design and development of new products has an extremely important position and role. Therefore, we should focus on innovative brands and trademarks rooted in the target market and adapt to the local cultural environment and their needs at the same time.

Before entering the Chinese market, multinational companies need to assess market opportunities and choose the right product. To make the multinational products sold to adapt to the needs of the Chinese market, should take full account of consumer habits, lifestyles and consumption value-oriented characteristics. Multinational companies should work hard in the packaging strategy [6]. In China, many consumers believe that packaging should be consistent with the product. If they are not fit, it tends to reduce the quality of the product. In addition, multinational efforts to attract Chinese customers can start from the brand. A successful brand is a company's most valuable assets.

Revelation to Channel Strategy. In a long period of time, very few people pay attention to cultural factors in the localization of marketing channels. Research is focused on the corporate image, culture and advertising. In fact, the impact of local culture to the marketing channels can not be ignored. From the cultural point, the choice of distribution channels is essential for consumers. Because the delicate relationship between the sales model and consumers are achieved through direct contact, and thus the product distribution plays an important role on the cultural infiltration. In order to reach the consumer goods at lower shipping costs, multinationals need to focus on building an efficient, low-cost logistics distribution network. Due to the complex factors involved in distribution management, there is no common and consistent way for the multinationals [7]. Therefore, Transnational Corporations should study on distribution channels in the Chinese market, and find effective distribution channels, and make adjustments to maintain the high efficiency of the distribution channels to adapt to changes in the environment[8].

customer value.

\section{Conclusion}

Facing with collectivism, weak uncertainty avoidance, flexible tendency and long-term oriented Chinese culture, multinational companies may feel frustrated. But the transfer the frustration into an opportunity can make them powerful. The cultural origins and cultural backgrounds of a certain nation constitute its unique cultural characteristics. Different values, language, customs, education level, religion rooted in the nation's traditional culture result in cultural marketing, that is to say, multinational companies in international market must resort to or adapt to different culture to make its marketing strategy. In fact, cultural marketing means a series of acts by using marketing policy that is based on unique cultural characteristics to establish a good image and gain reputation of the company and its products, build the confidence of its target customer, so as to achieve the expansion of sales channels, expand product sales in general. The company usually makes cultural marketing by adapting to the unique cultural atmosphere or creating certain cultural needs by adopting positive cultural marketing initiatives.

\section{References}

[1] Hofstede, Culture’s Consequence: International differences of work-related values.Beverly Hills, CA: Sage, 1980.

[2] L.H. He, H. Zhou. Theory of multinationalcorporations in China cross-cultural management evaluation index system of building.Journal of zhongzhou,2008,05:59-62.

[3] Y.Gui, Y. li. Multinational companies marketing strategy in the cross-cultural communication. Journal of hubei institute of technology, 2002,01:78-80. 
[4] X.J.Gu. Multinational in China. Journal of cross-cultural marketing strategy research reform and strategy, 2011,01:54 -56+ 95.

[5] X.Z. Liang. Multinational company of global marketing strategies and marketing activities in China. Journal of business research, 2007 ,03: 129-133+142.

[6]W.S. Mao, J.C. Wang. Multinational corporations in China strategic choice and strategy research. Journal of management science, 2009,02:117-125.

[7]L. Yu. Shallow theory of cultural marketing and its application in multinational companies. Journal of modern business, 2009,02:116.

[8]Z.M. Shen. Cultural marketing and product strategy of multinational corporation international marketing. Journal of business culture, 1997,06:32-34. 